\title{
Acardiac Twin-Twin Reversed Arterial Perfusion Sequence
}

\section{Sun-Gyoeng Kim, Hui-Gyeong Seo, Yun-Sook Kim}

Department of Obstetrics and Gynecology, Soonchunhyang University Cheonan Hospital, Soonchunhyang University College of Medicine, Cheonan, Korea

\begin{abstract}
In general, twin pregnancy represents a high-risk pregnancy. The monozygous twin of all twin pregnancy is a real challenge for the obstetrician due to the severe complications that may arise during its development. An extremely uncommon, severe complication of monozygous twin pregnancy, which we recently experienced in Soonchunhyang University Cheonan Hospital, was a monochorionic diamniotic twin pregnancy with acardiac twin-twin reversed arterial perfusion sequence. An acardiac twin presented no heart, underdeveloped inferior part of the body, being transfused by the other fetus (pumping twin) by umbilical vessels. We report a 33-year-old pregnant woman, with a history of in vitro fertilization-embryo transfer in the second pregnancy, who presented with generalized edema, abdominal discomfort, and high blood pressure at 33 weeks' gestation. By ultrasonography, one of the babies is normally developed but in the other baby, head, upper extremities, and cardiac activity cannot be detected. The pumping twin was cardiomegaly, polyhydramnios, absent diastolic wave on the umbilical artery, and small for gestational age. We decided to terminate the pregnancy by primary cesarean section after administration of corticosteroids. The comprehension of this case is compulsory in order to provide maximum survival opportunity to the viable baby.
\end{abstract}

Keywords: Pumping twin; Acardiac twin; Monozygous twin pregnancy; Twin reversed arterial perfusion

\section{INTRODUCTION}

The prevalence of twin reversed arterial perfusion (TRAP) sequence is less than $1 \%$ in cases of monozygous twin pregnancies [1]. It is the severe symptom of the twin-to-twin transfusion syndrome. The recipient twin (acardiac fetus) presents as a parasite, depending on the pumping twin (normal fetus) for its blood supply by transplacental anastomoses and reversed perfusion of the umbilical cord [2]. In an acardiac twin, the malformation noticed has typical aspects. The heart is missing or non-functioning, and the head, upper body and extremities, are incompetently developed. But the lower body and extremities are normal in greater or lesser degree [3]. For the pump twin, the outcome is bad, leading to a $50 \%$ to $75 \%$ mortality rate without treatment due to heart failure, preterm birth, or polyhydramnios [4]. Exact prenatal ultrasonographic diagnosis and proper treatment of complications arising acardiac twins is important in order to get a better prognosis for normal pumping twin.

\section{CASE REPORT}

A 33-year-old Korean two multigravida patient admitted to Soonchunhyang University Cheonan Hospital because of generalized edema, abdominal discomfort, and high blood pressure at 33 weeks' gestation. First baby was two years old, obtained from in vitro fertilization-embryo transfer due to both tubal obstruction. She had only one left frozen embryo. She had one embryo implanted for this pregnancy. At 8 weeks of pregnancy, the ultrasonography showed monochorionic diamniotic twin with one normal baby, another no heart. She was misdiagnosed single fetal death during the first trimester. The course of the pregnancy was uneventful from then to 20 weeks of gestation. She moved to another hospital at 22 weeks of gestation. At that hospital, the doctor said wrong that the dead fetus was surrounded with a swollen ring which it would be disappeared soon. But she felt continual growth of the dead fetus, abdominal bloating, sudden weight gain, and headache at 33 weeks' gestation. So she visited our clinic to know 
anything unusual. Heart activity was rhythmic in the first fetus, rate was 148 beats per minute, estimated weight was consistent with 29 weeks, and polyhydramnios (amniotic fluid index $=200$ ), cardiomegaly, absent umbilical arterial diastolic flow, and no anomalies were detected. In the second fetus, the fetal heart, cranium, and upper extremities could not be observed. The abdomen of the second fetus was surrounded with a large multiseptated cystic mass and spine and short lower extremities were seen (Fig. 1). Umbilical flows were circulated by reversed perfusion flows from that of the recipient twin. On Doppler ultrasonography, umbilical arterial systolic/diastolic ratio increased in the pump twin. We diagnosed monochorionic diamniotic twin pregnancy, presence of hydropic, and acardiac and acephalic twin with a TRAP sequence. Fetal surveillance with nonstress tests showed a nonreassuring fetal status. So we decided to deliver the fetus after corticosteroid therapies because there was a risk of stillbirth of pumping twin.

On physical examination, the patient had a body weight of 74 $\mathrm{kg}$, a blood pressure of 150/100 $\mathrm{mmHg}$, a pulse rate of 110 beats/ $\mathrm{min}$, a respiratory rate of 20 breaths/min, and a normal body temperature. The patient showed hemoglobin was $10.3 \mathrm{~g} / \mathrm{dL}$ (range,
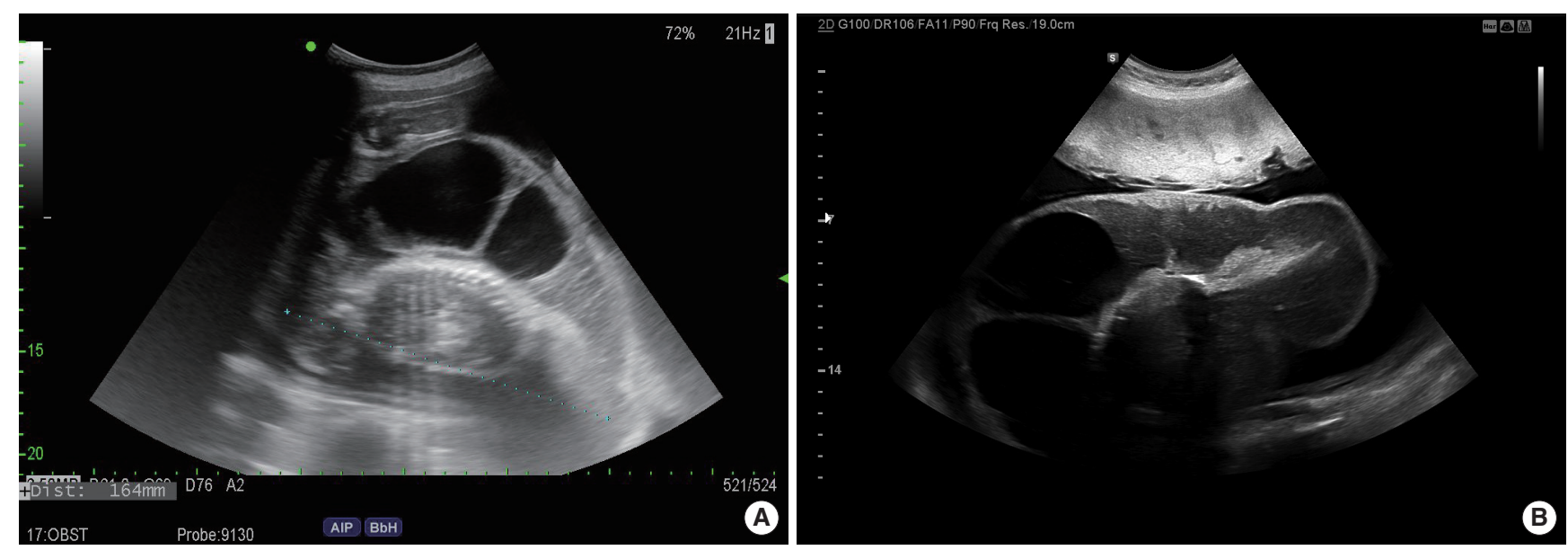

Fig. 1. The abdomen of the fetus was surrounded with a large multiseptated cystic mass, and (A) spine and (B) short lower extremities were seen by prenatal ultrasonography.
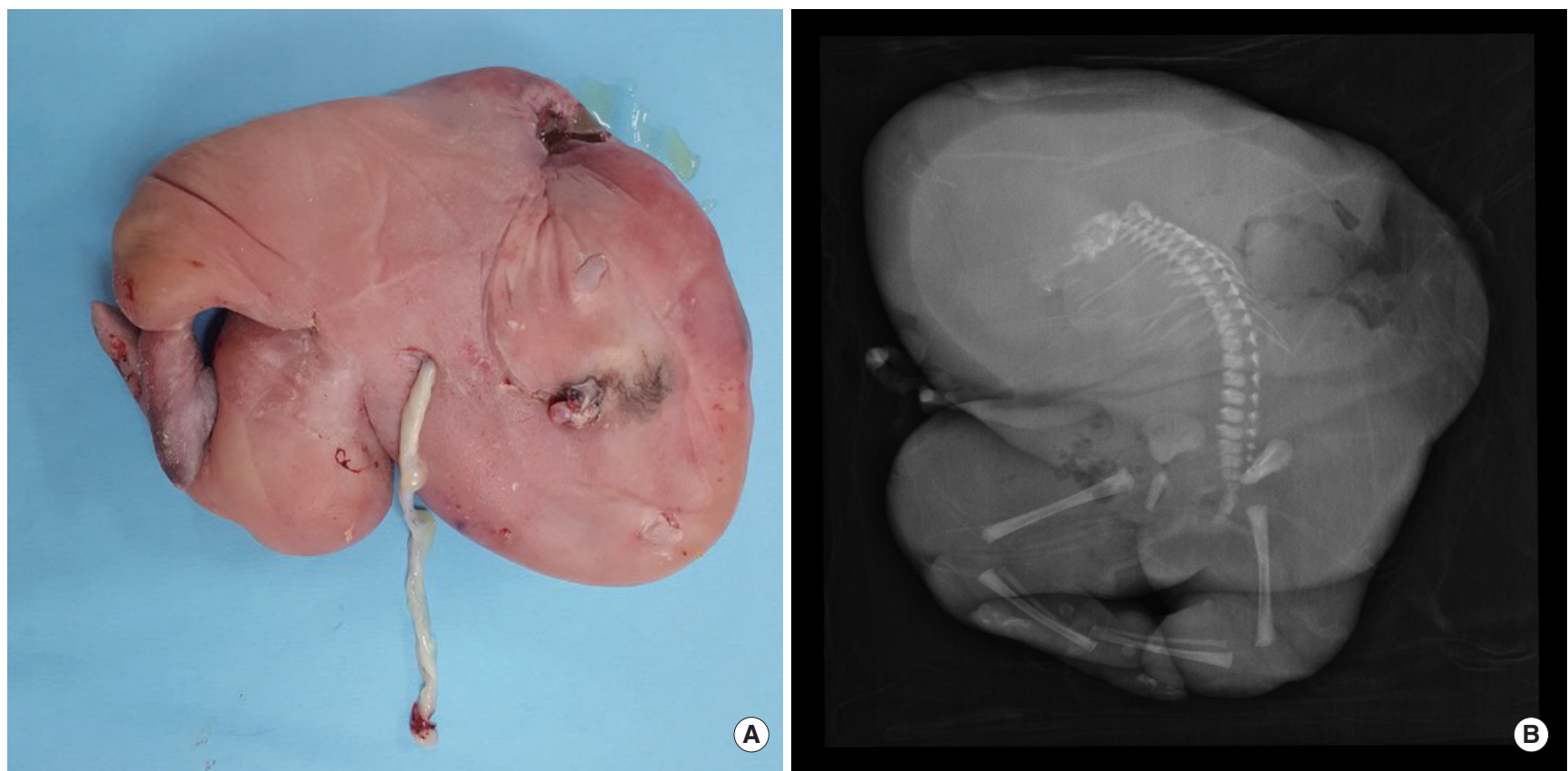

Fig. 2. The second acardiac fetus was 2,020 $\mathrm{g}$ and $32 \mathrm{~cm}$ in length with hydropic and acephalic by (A) gross and (B) infantogram. 
Kim SG, et al. - Acardiac Twin-Twin Reversed Arterial Perfusion Sequence

12.0 to $16.0 \mathrm{~g} / \mathrm{dL}$ ), white blood cell $14.510^{\wedge} 3 / \mu \mathrm{L}$ (range, 4.0 to 10.8 $10^{\wedge} 3 / \mu \mathrm{L}$ ), and platelet $261 / \mathrm{mm}^{3}$ (range, 130 to $400 / \mathrm{mm}^{3}$ ). Urine protein was +1 . Serum biochemistry and coagulation profiles were within normal limits. The patient was negative for hepatitis $B$, syphilis, and human immunodeficiency viruses.

A healthy 1,600 g, Apgar score of 6 and 8 at one and five minutes, and female baby with no abnormalities was born by cesarean section a day after admission. The baby was sent to the neonate intensive care unit because of preterm birth and small for gestational age. The second baby was 2,020 g with hydropic, acardiac, and acephalic (Fig. 2). Four days after her delivery, she was discharged with no complications. Her baby was discharged after a month with healthy state.

\section{DISCUSSION}

TRAP sequence is a special form of conjoined twins. The pathogenesis is suggested the developmental defects resulted from anastomoses in the placental vessels during the early developmental period [5]. In TRAP sequence, placenta blood flow between recipient fetus and pumping fetus is provided by artery to artery and vein to vein anastomosis on the placental bed [6]. The acardiac twin receives these poor oxygen blood, coming from pumping twin flows reversely in arteries of the acardiac fetus. So normal tissues of this fetus are partially atrophic, especially higher in the cranial and upper parts of extremities [7]. The acardiac twin have to be diagnosed by ultrasonography at the end of the first trimester. We reports which describe acardiac twin who was missed on ultrasound at early pregnancy and only detected at 33 weeks of gestation. Hence, obstetrician should be careful before diagnosing an unusual multifetal gestations. Prenatal ultrasonography shows absence of the heart, head, thorax, and upper extremities. The Doppler may show reversed vascular flows on placental vascular anastomoses [8]. According to the severity of defect, acardiac anomalies are divided into four categories. (1) Acardiac acephalic: the baby has developed lower extremities and pelvis. Head, thorax, and arms are absent. This is the most common type with a frequency of $60 \%$ to $75 \%$. Our case was in this group. (2) Acardiac anceps: the body and extremities have developed. Head and face are partially formed. This type consists about $20 \%$ of all cases. (3) Acardiac acormus: only the fetal head has developed. It is very rare and consists about $10 \%$ of all cases. (4) Acardiac amorphous: the fetus has no visible organs. It is extremely rare and it consists about
$5 \%$ of all cases [3].

The mortality of acardiac twin is $100 \%$. Mortality of pump twin is approximately $50 \%$ and the cause of death may generally be due to congestive heart failure and preterm birth arisen from polyhydramnios [9]. Chromosomal abnormalities are reported as about $9 \%$ [4]. But we could not perform due to late diagnosis. Early diagnosis is very important to determine the therapy. Proper treatment is discontinuation of the blood flow to the acardiac twin. These methods include endoscopic laser coagulation, sclerosis with alcohol, and thermocoagulation of the umbilical cord [10]. One of the most important prognostic factors is the ratio of the weight of the acardiac twin to the pumping twin (\%). If this ratio is above $70 \%$, preterm delivery is seen in $90 \%$, polyhydramnios in $40 \%$, and heart failure in $30 \%$. But it is nearly impossible to estimate the weight of the acardiac twin prenatally [4]. Bad prognostic factors are continual growth of the acardiac twin, polyhydramnios, cardiomegaly, pericardial effusion, and low pulsatility index in the umbilical artery of the pumping twin [5]. The ultrasonography, non-stress test, and biophysical profile are needed serially [11]. The pumping twin of this case was detected polyhydrmnios, small for gestational age, cardiomegaly, absent umbilical arterial diastolic flow.

In conclusion, TRAP sequence is a very rare form that is seen in monochorionic twin pregnancies and it has a high mortality. Early exact diagnosis and proper treatment are important in order to get a better prognosis for normal pumping twin.

\section{REFERENCES}

1. Hecher K, Ville Y, Nicolaides KH. Color Doppler ultrasonography in the identification of communicating vessels in twin-twin transfusion syndrome and acardiac twins. J Ultrasound Med 1995;14:37-40.

2. Van Allen MI, Smith DW, Shepard TH. Twin reversed arterial perfusion (TRAP) sequence: a study of 14 twin pregnancies with acardius. Semin Perinatol 1983;7:285-93.

3. Langlotz H, Sauerbrei E, Murray S. Transvaginal Doppler sonographic diagnosis of an acardiac twin at 12 weeks gestation. J Ultrasound Med 1991;10:175-9.

4. Wong AE, Sepulveda W. Acardiac anomaly: current issues in prenatal assessment and treatment. Prenat Diagn 2005;25:796-806.

5. Anca FA, Negru A, Mihart AE, Grigoriu C, Bohiltea RE, Serban A. Special forms in twin pregnancy-ACARDIAC TWIN: twin reversed arterial perfusion (TRAP) sequence. J Med Life 2015;8:517-22.

6. Rohilla M, Chopra S, Suri V, Aggarwal N, Vermani N. Acardiac-acephalus twins: a report of 2 cases and review of literature. Medscape J Med 2008;10:200.

7. Kim JA, Cho JY, Lee YH, Song MJ, Min JY, Lee HJ, et al. Complications arising in twin pregnancy: findings of prenatal ultrasonography. Korean J Radiol 2003;4:54-60. 
8. Peyvandi S, Feldstein VA, Hirose S, Rand L, Brook MM, Moon-Grady AJ. Twin-reversed arterial perfusion sequence associated with decreased fetal cerebral vascular impedance. Ultrasound Obstet Gynecol 2015;45: 447-51.

9. Ahmad I, Sabzposh NA, Ahmad M, Siddiqui MA. Diagnostic dilemma in twin-reversed arterial perfusion sequence. J Obstet Gynaecol India
2013;63:282-4.

10. Tayal T, Kaul A. Intrafetal laser ablation of umbilical vessels in acardiac twin with successful outcome. J Obstet Gynaecol India 2012;62(Suppl 1):43-5.

11. Kiran P, Sangeeta A, Geetanjaly K. A rare case of acardiac acephalus twin pregnancy. J Obstet Gynecol India 2010;1:75-6. 